\title{
DIFFERENCES IN BODY MASS INDEX AND SERUM LIPID PROFILE AMONG VEGETARIANS \& NON VEGETARIANS
}

\author{
Suja $\mathrm{P}^{1}$, Shrinidhi², Prarthana $\mathrm{K} \mathrm{G}^{3}$, Bharath $\mathrm{T}^{4}$
}

\section{HOW TO CITE THIS ARTICLE:}

Suja P, Shrinidhi, Prarthana KG, Bharath T. "Differences in body mass index and serum lipid profile among vegetarians \& non vegetarians". Journal of Evolution of Medical and Dental Sciences 2013; Vol2, Issue 35, September 2; Page: 6766-6771.

\begin{abstract}
AIM: To study the body mass index (BMI) and serum lipid profile in vegetarians compared to nonvegetarians. MATERIALS AND METHODS: This is a cross sectional study designed to study the correlation of BMI and serum lipid profile among vegetarians and non-vegetarians $(n=25$ in each group) aged between 18-40 years. BMI was measured and fasting blood sample was drawn for analysis of lipids. Information was obtained on personal and family health history, health-related habits including leisure-time physical activity and dietary intake. RESULTS: Vegetarians have a lower mean BMI and lower dietary intakes of protein, saturated fat and cholesterol compared to non-vegetarians. Vegetarians have significantly lower concentrations of serum total cholesterol (TC), low density lipoprotein (LDL), triglycerides (TG), TC/high density lipoprotein (HDL) and LDL/HDL than the non-vegetarians.
\end{abstract}

KEYWORDS: Body mass index, Lipid profile, Vegetarians, Non-Vegetarians

INTRODUCTION: Overweight and obesity are the new global health threats. This is mainly due to sea change in our food habits. There is excessive intake of imbalanced and calorie rich foods among children and adolescents. This can lead to chronic ailments like hypercholesterolemia, hypertension, diabetes mellitus and major depressive disorder ${ }^{1}$. According to World Health Organization (WHO) ${ }^{2}$, globally around 2.8 million people die every year as a consequence of being overweight or obese; and in the last 30 years, the prevalence of obesity has nearly doubled worldwide. This study makes a small attempt in understanding one of the many dimensions of the effects produced by the type of dietary intake, by studying the BMI and serum lipid profile in vegetarians compared to nonvegetarians.

MATERIALS AND METHODS: This cross sectional study was carried out in A J institute of Medical Sciences and Research Centre, Mangalore between June 2010 and September 2010. Fifty apparently healthy subjects aged between 18-40 years were included in the study. Subjects with family history of hypercholesterolemia, subjects on drugs that affect the lipid profile were excluded from the study. Subjects were assigned to two groups: vegetarians (veg) and non-vegetarians (non-veg) based on the diet consumed. Ethical clearance was obtained from institute's ethical committee and written informed consent was obtained from all the subjects. History of dietary habits, physical activity, family history and any health disorders were documented. Height was measured to the nearest 0.1 centimeters using wall mounted stadiometer and weight was measured to the nearest $100 \mathrm{~g}$ using a standard weighing scale. BMI was calculated using the Quetelet's index: weight $(\mathrm{kg}) / \mathrm{height}$ (metre) ${ }^{2}$. The subjects were divided into three categories: obese, overweight and normal according to WHO guidelines ${ }^{3}$. An early morning blood sample was collected from all the subjects after an overnight fast of 10 hours to assess serum lipid profile. Serum TC, LDL, TG, HDL, TC/HDL, and 
LDL/HDL levels were analyzed using a semi automated analyzer. All tests were conducted free of cost for the study subjects. Chi square was done to test the difference in BMI and lipid profile between veg and non-veg group.

RESULT: The average age of the subjects in the study group was 23.4 years in veg and 26.6 years in non-veg group. Table 1 shows the mean height, weight and BMI in veg and non-veg group. The mean height in veg and non-veg group was $1.63 \mathrm{~m}$ and $1.62 \mathrm{~m}$ respectively. The weight comparison done in both the groups showed a statistically significant difference between the two groups. The mean BMI (Graph 1) was significantly higher $(\mathrm{p}=0.002)$ in non-veg group compared to veg group. Moreover, non-veg group had poorer dietary patterns like high intake of fat and processed meat at least thrice a week with frequent visit to restaurants, they had lesser consumption of vegetables, fruits and fiber rich foods, they had energy intake higher than the estimated energy requirement for age and gender. Among the veg group: 20 subjects were in normal weight range, 2 subjects were underweight, 3 subjects were overweight. Among the non-veg:15 subjects were in normal range, 9 subjects were overweight and 1 subject was obese. There was a statistically significant association between BMI and dietary pattern between two groups. Non-veg group had a higher risk of being overweight and obese compared to veg.

Table 1: Comparison of height, weight, BMI in vegetarians and non-vegetarians

\section{Group Statistics}

\begin{tabular}{|ll|r|r|r|c|}
\hline & GROUP & \multicolumn{1}{|c|}{$\mathrm{N}$} & \multicolumn{1}{c|}{ Mean } & Std. Deviation & $\mathrm{t}$ \\
\hline $\mathrm{HT}$ & Veg & 25 & 1.6272 & .08080 & .31100 \\
& Non veg & 25 & 1.6200 & .08287 & $\mathrm{p}=.757 \mathrm{~ns}$ \\
\hline WT & Veg & 25 & 58.2400 & 8.97348 & 2.20100 \\
& Non veg & 25 & 64.5200 & 11.09474 & $\mathrm{p}=.033 \mathrm{sig}$ \\
\hline BMl & Veg & 25 & 21.9108 & 2.38064 & 3.25600 \\
& Non veg & 25 & 24.4672 & 3.12111 & $\mathrm{p}=.002 \mathrm{hs}$ \\
\hline
\end{tabular}

\section{Graph 1: BMI in vegetarians and non-vegetarians}

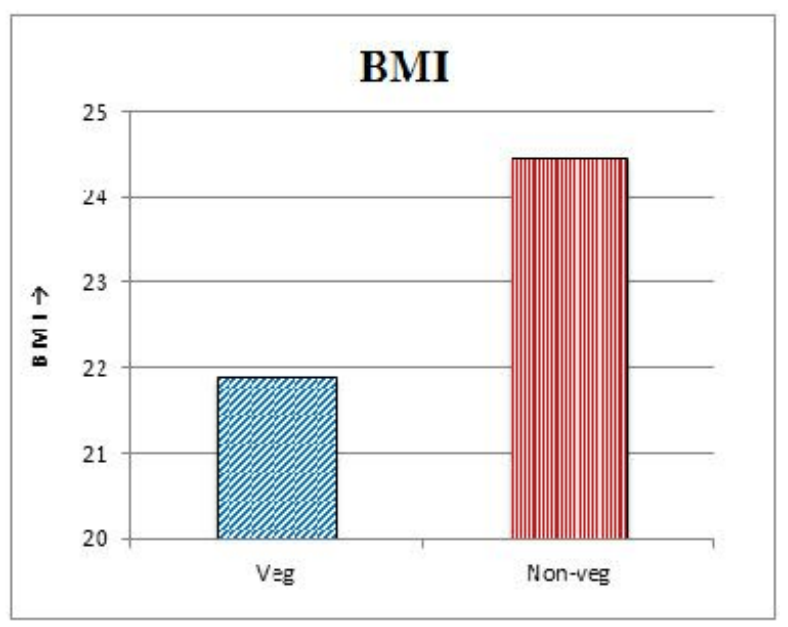


Among the non-veg group, TC (Graph 2) and LDL (Graph 3) values were higher compared to veg group which was statistically significant. The other parameters viz TG, VLDL, TC/HDL, LDL/HDL showed higher values in non-veg group but was not statistically significant. HDL level remained within normal range in both the groups. (Table 2)

Table 2: Comparison of lipid profile in vegetarians and non-vegetarians

\begin{tabular}{|c|c|c|c|c|}
\hline $\begin{array}{l}\text { Lipid profile } \\
\text { (mg/dl) }\end{array}$ & Veg (n-25) & Non-veg $(n=25)$ & $\mathbf{x}^{2}$ & $\mathbf{p}$ \\
\hline $\begin{array}{l}\text { Total cholesterol } \\
<150 \\
150-250 \\
>250\end{array}$ & $\begin{array}{l}11 \\
14 \\
00\end{array}$ & $\begin{array}{l}03 \\
20 \\
02\end{array}$ & 7.63 & 0.022 (sig) \\
\hline $\begin{array}{l}\text { Triglyceride } \\
<48 \\
48-180 \\
>180\end{array}$ & $\begin{array}{l}02 \\
19 \\
04\end{array}$ & $\begin{array}{l}01 \\
22 \\
02\end{array}$ & 1.22 & 0.542 (not sig) \\
\hline $\begin{array}{l}\text { LDL } \\
<70 \\
70-130 \\
>130\end{array}$ & $\begin{array}{l}07 \\
18 \\
00\end{array}$ & $\begin{array}{l}03 \\
16 \\
06\end{array}$ & 7.77 & 0.021 (sig) \\
\hline $\begin{array}{l}\text { VLDL } \\
<10 \\
10-50 \\
>50\end{array}$ & $\begin{array}{l}02 \\
21 \\
02\end{array}$ & $\begin{array}{l}01 \\
22 \\
02\end{array}$ & 0.357 & 0.837 (not sig) \\
\hline $\begin{array}{l}\text { HDL } \\
35-75\end{array}$ & 25 & 25 & & \\
\hline $\begin{array}{l}\text { LDL/HDL } \\
<2.5 \\
2.5-3.5 \\
>3.5\end{array}$ & $\begin{array}{l}19 \\
03 \\
03\end{array}$ & $\begin{array}{l}20 \\
01 \\
04\end{array}$ & 1.168 & 0.558 (not sig) \\
\hline $\begin{array}{l}\text { TC/HDL } \\
<3.7 \\
3.7-4.3 \\
>4.3\end{array}$ & $\begin{array}{l}20 \\
04 \\
01\end{array}$ & $\begin{array}{l}17 \\
05 \\
03\end{array}$ & 1.354 & 0.508 (not sig) \\
\hline
\end{tabular}


Graph 2: Total Cholesterol in vegetarians and non-vegetarians

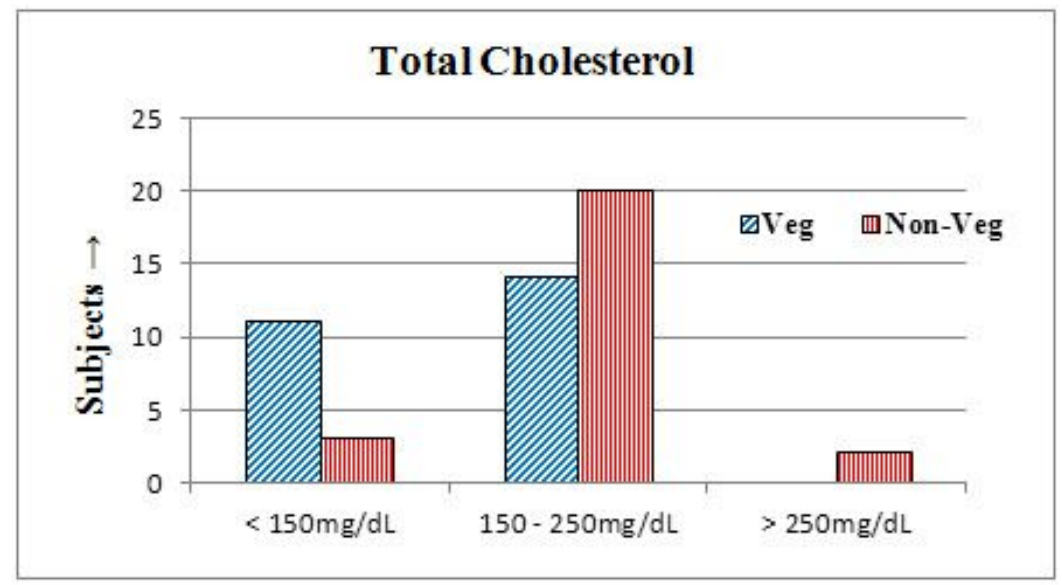

Graph 3: LDL in vegetarians and non-vegetarians

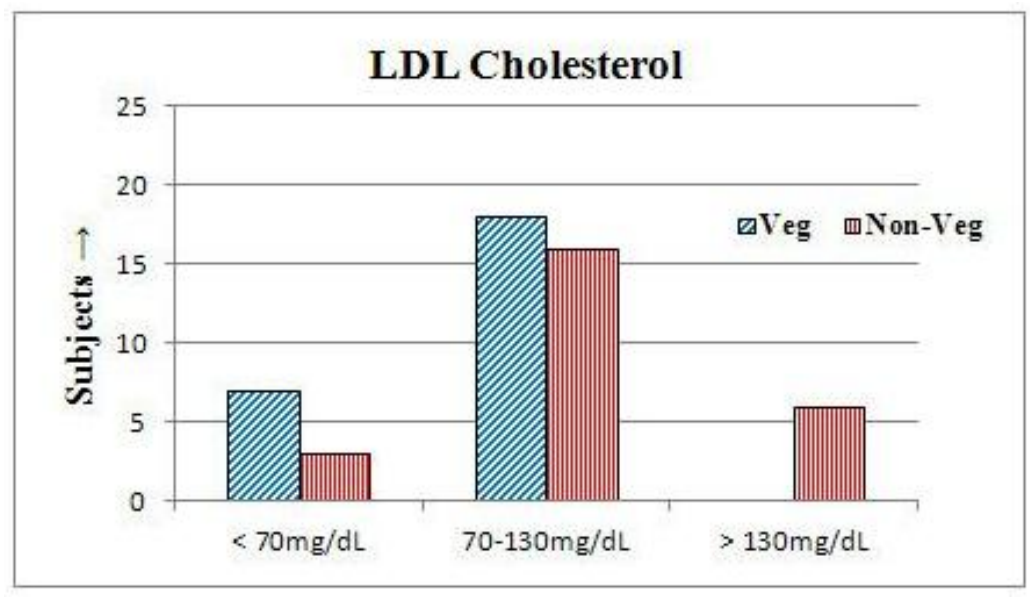

DISCUSSION: According to Johansson et $\mathrm{al}^{4}$, obesity seems to be the new global pandemic in the present century. It is estimated that 1.5 billion people are suffering from the effects of obesity and overweight. Variety of factors including unhealthy food habits like high intake of processed food rich in transfats, sugar and empty calories are implicated. Gradual reduction in healthy habits has compounded the problem ${ }^{4}$. The study on vegetarians by Jacka et $\mathrm{al}^{5}$ has shown that consumption of nutrient rich foods have positive effects on redox status and immune system functioning.

The present study attempts to understand the correlation between increased intake of nonvegetarian food, weight gain and lipid levels. Studies by Zhang et $\mathrm{a}^{6}$, Delisle et $\mathrm{al}^{7}$ and Uusitupa et $\mathrm{al}^{8}$ have shown positive correlation between diet, obesity and BMI. The present study is in agreement with the previous studies. In this study we found that obesity and overweight is more common in subjects with non-vegetarian diet. Frazier-wood et $\mathrm{al}^{9}$, Jitnarin et $\mathrm{al}^{10}$ and Delisle et $\mathrm{al}^{11}$ have studied the association between BMI and diet. They have found that it is attributable to multiple factors in addition to diet, like genetic factors, sedentary life style and urbanization. Increased BMI is associated with atherogenic factors like higher TC and LDL level. Our study conclusively proves this 


\section{ORIGINAL ARTICLE}

point. In the present study; we found that the HDL levels were within the normal range in both veg and non-veg group. In contrast, the HDL levels were lower in non-veg group, in a study done by Bobbioni et al $^{12}$.

Large scale studies by Múnera et al ${ }^{13}$ and Molina et al ${ }^{14}$ have shown that obesity is a contributing factor to cardio metabolic risk in younger age group. In the present study, simple measures like assessment of BMI have been found to be contributory to metabolic screening in adolescent population. Study by Cugnetto et al ${ }^{15}$ have found out strong association between diet and coronary artery diseases in adolescents.

CONCLUSION: In the present study, there is a positive correlation between BMI, serum lipid profile and the type of diet. So, there is a need to encourage healthy dietary patterns, enhanced physical activity and regular assessment of biochemical parameters among young adults.

\section{REFERENCES:}

1. Lang T, Reshaping the food system for ecological public health. Journal of Hunger \& Environmental Nutrition.2009; 4 :315-335.

2. WHO: Global health observatory (GHO) [internet]. 2013 [cited 21 August 2013]. Available from : http://www.who.int/gho/ncd/risk_factors/obesity_text/en/

3. WHO: Global database on Body Mass Index [internet].2013 [cited 14 August 2013].Available from : http://apps.who.int/bmi/index.jsp?introPage=intro_3.html

4. Johansson I, Nilsson LM, Stegmayr B, Boman K, Hallmans G, Winkvist A. Associations among 25-year trends in diet, cholesterol and BMI from 140,000 observations in men and women in Northern Sweden. Nutrition Journal 2012; 1-13.

5. Jacka FN, Kremer PJ, Berk M, Silva-sanigorski AM De, Leslie ER, Pasco JA, et al. A Prospective Study of Diet Quality and Mental Health in Adolescents. PLoS one 2011; 6(9):1-7.

6. Zhang HJ, Han P, Sun SY, Wang LY, Yan B, Zhang JH et al. Attenuated associations between increasing BMI and unfavorable lipid profiles in Chinese Buddhist vegetarians. Asia Pac J ClinNutr 2013; 22(2):249-56.

7. DelisleH, Ntandou G, Sodjinou R, Couillard C, Després JP. At-risk serum cholesterol profile at both ends of the nutrition spectrum in West African adults, The Benin study. Nutrition2013; 5(4):1366-83.

8. Uusitupa M, Hermansen K, Savolainen MJ, Schwab U, Kolehmainen M, Brader L et al. Effects of an isocaloric healthy Nordic diet on insulin sensitivity, lipid profile and inflammation markers in metabolic syndrome - a randomized study (SYSDIET). J Intern Med 2013; 274(1):52-66.

9. Frazier-wood AC, Kabagambe EK, Borecki IB, Tiwari HK, Jose M, Arnett DK. Preliminary Evidence for an Association between LRP-1 Genotype and Body Mass Index in Humans. PLoS one 2012; 7(2):8-11.

10. Jitnarin N, Kosulwat V, Rojroongwasinkul N, Boonpraderm A, Haddock CK, Poston WSC. Risk Factors for Overweight and Obesity among Thai Adults: Results of the National Thai Food Consumption Survey.Nutrition.2010:60-74.

11. Delisle H, Ntandou-Bouzitou G, Agueh V, Sodjinou R, Fayomi B. Urbanisation, nutrition transition and cardiometabolic risk: the Benin study. Br J Nutr 2012; 107(10):1534-44. 


\section{ORIGINAL ARTICLE}

12. Bobbioni-Harsch E, Pataky Z, Makoundou V, Laville M, Disse E, Anderwald C et al. From metabolic normality to cardiometabolic risk factors in subjects with obesity. RISC Investigators Obesity (silver spring.) 2012; 20(10):2063-9.

13. Múnera NE, Uscátegui RM, Parra BE, Manjarrés LM, Patiño $F$, Velásquez $\mathrm{CM}$ et al. Environmental risk factors and metabolic syndrome components in overweight youngsters. Biomedica 2012; 32(1):77-91.

14. Molina JJM, Oliveras, López MJ, Mayor Reyes M, Burgos TR, García de la Serrana LH. Influence of physical activity and dietary habits on lipid profile, blood pressure and BMI in subjects with metabolic syndrome. Nutr Hosp Madrid 2011;26(5):1105-9

15. Cugnetto LM, Saab PG, Liabre MM, Goldberg R, Mc Culla JR, Schneidermann N. Lifestyle Factors, Body Mass Index, and Lipid Profile in Adolescents. J Pediatr Psychol. 2008; 33(7): 761-771.

\section{AUTHORS:}

1. Suja P.

2. Shrinidhi

3. Prarthana K.G.

4. Bharath T.

\section{PARTICULARS OF CONTRIBUTORS:}

1. Assistant Professor, Department of Physiology, Malabar Medical College and Research Centre, Calicut, India.

2. Post Graduate, Department of Physiology, A.J. Institute of Medical Sciences, Mangalore, India.

3. Assistant Professor, Srinivasa Institute of Medical Sciences and Research Centre, Mangalore, India.
4. Assistant Professor, Department of Physiology, Malabar Medical College and Research Centre, Calicut, India.

\section{NAME ADRRESS EMAIL ID OF THE CORRESPONDING AUTHOR:}

Dr. Suja P, Assistant Professor, Dept. of Physiology, Malabar Medical College and Research Centre, Modakkallur, Atholi, Calicut - 673315, Kerala, India.

Email - sujashishir@gmail.com

Date of Submission: 14/08/2013. Date of Peer Review: 15/08/2013. Date of Acceptance: 24/08/2013. Date of Publishing: 30/08/2013 